\title{
Compartment syndrome: challenges and solutions
}

This article was published in the following Dove Press journal:

Orthopedic Research and Reviews

4 November 2015

Number of times this article has been viewed

\section{Kohila Sigamoney \\ Pratima Khincha \\ Ravi Badge \\ Nikhil Shah \\ Department of Orthopaedics, Wrightington, Wigan and Leigh NHS Foundation Trust, Wigan, UK}

Correspondence: Ravi Badge

10 Holme Avenue, Wigan WNI 2EH, UK

Tel +44 77 780I 328I

Email raviorth@gmail.com
Abstract: Compartment syndrome is defined as increased pressure within a fibro-osseous space resulting in decreased tissue perfusion to structures within that space. Hence, early identification is critical for successful outcomes. There are two types of compartment syndrome - acute and chronic. Out of the two, acute compartment syndrome (ACS) is more worrying and needs urgent attention. ACS can be caused by a number of factors. These can be broadly classified as factors causing increased volume within a closed space, or those that restrict the compartment from expanding. The mainstay of diagnosis is a high index of clinical suspicion particularly in high risk cases. The three main findings that point toward compartment syndrome which clinicians rely on are 1) pain out of proportion to expectation, 2) stretch pain, ie, pain exacerbated by passive movement/stretch of muscles within the compartment, and 3) tense swelling. Though there are no reproducible and reliable tests for compartment syndrome, measurement of intracompartmental syndrome is required in cases where diagnosis is unclear. Traditionally a measurement of $30 \mathrm{mmHg}$ was taken as a cut off value above which fasciotomy was necessary. A delta pressure of $30 \mathrm{mmHg}$ or less can also be used to indicate the need for fasciotomy. Delta pressure, is the difference between the diastolic blood pressure of a patient and the pressure of the compartment measured ( $\Delta \mathrm{P}=$ diastolic pressure - intracompartmental pressure). In terms of management, removal of any constrictive dressings is a critical step to allow accurate assessment of the limb. If there is a doubt then the diagnosis of ACS should be considered unless proven otherwise. Once the diagnosis is made, the treatment is surgical in the form of fasciotomy. The aim is to decompress the involved compartments. The suggestion however, is to decompress all compartments of the affected part of the limb. Compartment syndrome is a serious condition and every care must be taken to treat this condition as soon as possible.

Keywords: compartment syndrome, current challenges, solutions

\section{Introduction}

Compartment syndrome is defined as increased pressure within a fibro-osseous space resulting in decreased tissue perfusion to structures within that space. ${ }^{1}$ The disturbed microcirculation in an acute setting could lead to potentially irreversible neuromuscular ischemic damage, and its sequelae. ${ }^{2}$ Hence, early identification is critical for successful outcomes. ${ }^{3}$

Richard von Volkmann in 1881 was the first to describe compartment syndrome. ${ }^{4}$ There are two types of compartment syndrome - acute and chronic. ${ }^{1}$ Acute compartment syndrome (ACS) commonly occurs after limb trauma, commonly affecting the lower limb. Emergency treatment in the form of decompression by extensile fasciotomy is necessary in this situation. Chronic compartment syndrome typically presents with 
recurrent episodes of exercise-induced pain, commonly seen in athletes. ${ }^{2}$

Out of the two, ACS is more worrying and needs urgent attention. If ACS is not reversed within 8 hours by decompression, it will result in tissue necrosis. ${ }^{5}$ Undiagnosed cases, and delay in treatment lead to major financial burden in malpractice lawsuits, which though uncommon, are increasing in the modern day setting. ${ }^{6}$ The complications resulting from irreversible damage to skeletal muscle and nerves such as severe intractable pain, delayed fracture union, Volkmann's ischemic contracture, neurological deficit, gangrene, infection, loss of function and amputation have been well documented in literature. ${ }^{7,8}$ As McQueen et $\mathrm{al}^{9}$ emphasized, awareness among hospital staff is critical in early recognition of compartment syndrome, in order to prevent long-term disability.

As ACS is one of the orthopedic or surgical emergencies that require quick recognition and treatment, and can lead to significant morbidity or mortality, we have reviewed the most recent literature about this clinical entity along with the challenges faced and solutions attributed to that.

\section{Challenges}

Often, the challenges associated with ACS is having an accurate, prompt diagnosis and appropriate management. The diagnosis is mainly a clinical one and hence there could be difficulties in patients with unclear symptoms or in the obtunded patient, intoxication and in certain situations, one who has many co-morbidities or other distracting injuries.

The other difficulty is that compartment syndrome can be misdiagnosed by the inexperienced clinician. It can be missed by inadequate history taking, clinical examination or by inexperience in using the intracompartmental measuring device.

With regards to the management of compartment syndrome, the challenge posed is often about whether to do a fasciotomy in a patient with an unclear diagnosis, whether to perform prophylactic fasciotomy in a patient who is high risk, whether to perform fasciotomy in late presentation, or whether to release the affected compartment(s) only as opposed to all compartments within the affected limb.

\section{Etiology}

ACS can be caused by a number of factors. These can be broadly classified as factors causing increased volume within a closed space, or those that restrict the compartment from expanding. The former include bleeding (eg, due to fractures, coagulopathy), extravasation of intravenous or interosseous infusion, edema or accumulation of purulent material. Constrictive dressing, casting, inadvertent use of tourniquet, and burns prevent expansion of the fibro-osseous space causing compartment syndrome. ${ }^{4}$ Compartment syndrome after vascular injury is a result of ischemia and reperfusion injury. ${ }^{10} \mathrm{~A}$ list of factors that can cause compartment syndrome is shown in Table 1.

Isolated cases of compartment syndrome post-thrombolytic therapy for pulmonary embolism have been cited. ${ }^{11}$ Haggis et al, ${ }^{12}$ in a small yet important study of seven cases of ACS after total knee replacement found risk factors such as previous surgery, complex surgery, soft tissue compromise, use of tourniquet, and vascular injury as predisposing for development of ACS in these cases.

\section{Epidemiology}

High energy injuries and polytrauma increase the risk of ACS. McQueen et al, reported fractures were most often implicated in compartment syndrome, in as much as $69 \%$, as compared to $23.2 \%$ attributed to soft tissue injuries without fractures. ${ }^{9}$ Amongst fractures, most commonly observed were of the tibial diaphysis (36\%) and distal radius in 9.8\%. High index of suspicion must be maintained in closed, as well as open fractures of the lower limb.

In a systematic review by Ojike et al, ${ }^{13}$ it was found that 89 patients had thigh compartment syndrome, most commonly seen after blunt trauma (90\%). Another systematic review of 39 cases of foot compartment syndrome reported crush injury to be the most common cause. ${ }^{14}$ Complications of contractures, deformity, and paralysis were poorly tolerated in foot ACS. ${ }^{15} \mathrm{~A}$ small number of gluteal compartment syndrome has been cited in literature following prolonged immobilization, with risk of sciatic nerve injury. ${ }^{16,17}$

Table I Factors associated with compartment syndrome

\begin{tabular}{ll}
\hline Increased volume within & Prevention of expansion \\
compartment & \\
\hline Crush injury & Tourniquet \\
Fracture & Burns \\
Reperfusion injury & Constrictive dressings \\
Arterial injury & Casts \\
Insect bite & Extravasation of infusions \\
Prolonged tetanic contractions & \\
latrogenic & \\
Snake bite & \\
Penetrating trauma (gunshot and & \\
stab wounds) & \\
Post-thrombolytic therapy & \\
Bleeding disorder & \\
Phlebitis & \\
Thromboembolism & \\
Drug abuse &
\end{tabular}


In the adult forearm, distal radius fractures were found to be the most prevalent cause of compartment syndrome. ${ }^{18}$ However in one study by Elliott and Johnstone, ${ }^{19}$ soft tissue injuries without fracture $(23 \%)$ were more commonly implicated than fractures (18\%), thus emphasizing the myriad of factors that can lead to compartment syndrome. The risk of $0.25 \%$ with distal radius fracture, increases to $15 \%$ with ipsilateral distal radius and elbow injury, as reported by Hwang et al. ${ }^{20}$ Isolated cases of insect and snake bites in the upper limb have shown risk of compartment syndrome. Compartment syndrome in the hand can also result following high pressure injection to hand, commonly seen in the non-dominant index finger. ${ }^{21}$

In a review of the National Pediatric Trauma Registry, it was noted that in 131 children, $74 \%$ of ACS was attributed to forearm fractures and only $15 \%$ due to supracondylar fractures. ${ }^{22}$ It was suggested that the reason for the change in trend could possibly be due to better fracture management, with percutaneous pinning, and maintaining elbow flexion of 90 degrees or less in cast immobilization. ${ }^{23}$

\section{Pathophysiology}

Compartment syndrome is caused by the increase in pressure within the fibro-osseous space, which causes decreased tissue perfusion. Most commonly affected structures by microvascular compromise are skeletal muscles and nerves of that compartment.

The rise in intracompartmental pressure causes collapse of the venules, as they lack musculature. This in turn reduces the hydrostatic gradient, causing decreased local perfusion. Edema develops due to increased capillary permeability causing increased interstitial pressure. All these factors further increase the compartment volume leading to a vicious cycle. Vasospasm, shock, and elevation of the extremity result in decreased arteriolar pressure. This could possibly result in closure of arterioles, which also contributes to decreased local perfusion (Figure 1). ${ }^{4}$

Harvey et $\mathrm{al}^{8}$ in their review article, described damaged tissue itself rather than bleeding or collection of fluid, as a factor contributing to the increase in an intracompartmental volume. They also found inflammation to play a major role based on the newer studies. Lawendy et al conducted a study on rats. ${ }^{24}$ They maintained pressure of $30-40 \mathrm{~mm}$ of $\mathrm{Hg}$ in hind limbs for 90 minutes, and analyzed the extensor digitorum longus after fasciotomy. There was significantly more tissue injury in normal rats $(32 \% \pm 7 \%$ white cell count) following increased compartmental pressure, than neutropenic rats $(9 \% \pm 1 \%$ white cell count). In other studies, one showed increase in anti-inflammatory cytokines in increased compartmental pressure; and the second study demonstrated that tissue injury returned to almost baseline levels after administration of indomethacin. However, this still requires further investigation, but it provides scope for new forms of non-surgical intervention for patients. ${ }^{6,8}$

\section{Diagnosis}

The mainstay of diagnosis is a high index of clinical suspicion particularly in high risk cases. However difficulty can be encountered in diagnosing compartment syndrome based on clinical picture alone, as the signs and symptoms can be ambiguous. ${ }^{25}$ Diagnosis is challenging, and can be missed despite clinical vigilance. This is more important in obtunded patients, polytrauma and in the presence of equivocal clinical findings, head injury, unconsciousness, and perioperative narcotics, where the clinical picture is clouded. Nerve blocks are often stated to "mask" a compartment syndrome. This is proven not exactly the case. If a patient experiences pain in the presence of a functioning nerve block, this is a sign of imminent compartment syndrome. Therefore, the late diagnosis of compartment syndrome here is usually due to lack of clinical experience. ${ }^{26}$ In all such cases, there is a need for objective diagnostic measurement. Kalyani et $\mathrm{al}^{18}$ in their systematic review noted that in $48 \%$ patients, diagnostic criteria was based on clinical picture alone, and in 52\% patients, both clinical assessment and intracompartmental measure was used to establish compartment syndrome, showing almost equal distribution in both categories.

\section{Clinical assessment}

The five "P"s that have been described historically in relation to compartment syndrome - pain, pulselessness, paresthesia, pallor, and paralysis are signs of ischemia and not compartment syndrome. However, the three main findings that point toward compartment syndrome which clinicians rely on are: 1) pain out of proportion to expectation, 2) stretch pain, ie, pain exacerbated by passive movement/stretch of the muscles, and 3 ) tense swelling. ${ }^{4,5,25}$ In addition to this, hypoesthesia as a reliable finding has been supported by some studies. ${ }^{18}$

However, as these findings are not absolute and have observer variation, it is difficult to rely only on clinical findings in all cases. One must maintain a high index of suspicion, and often supplementation of diagnosis by testing is required. This is required more so in patients who are unable to communicate, uncooperative, unconscious, and in children. Bae et $\mathrm{al}^{23}$ also found that the increased need for analgesia was supportive in pediatric patients of a compartment 


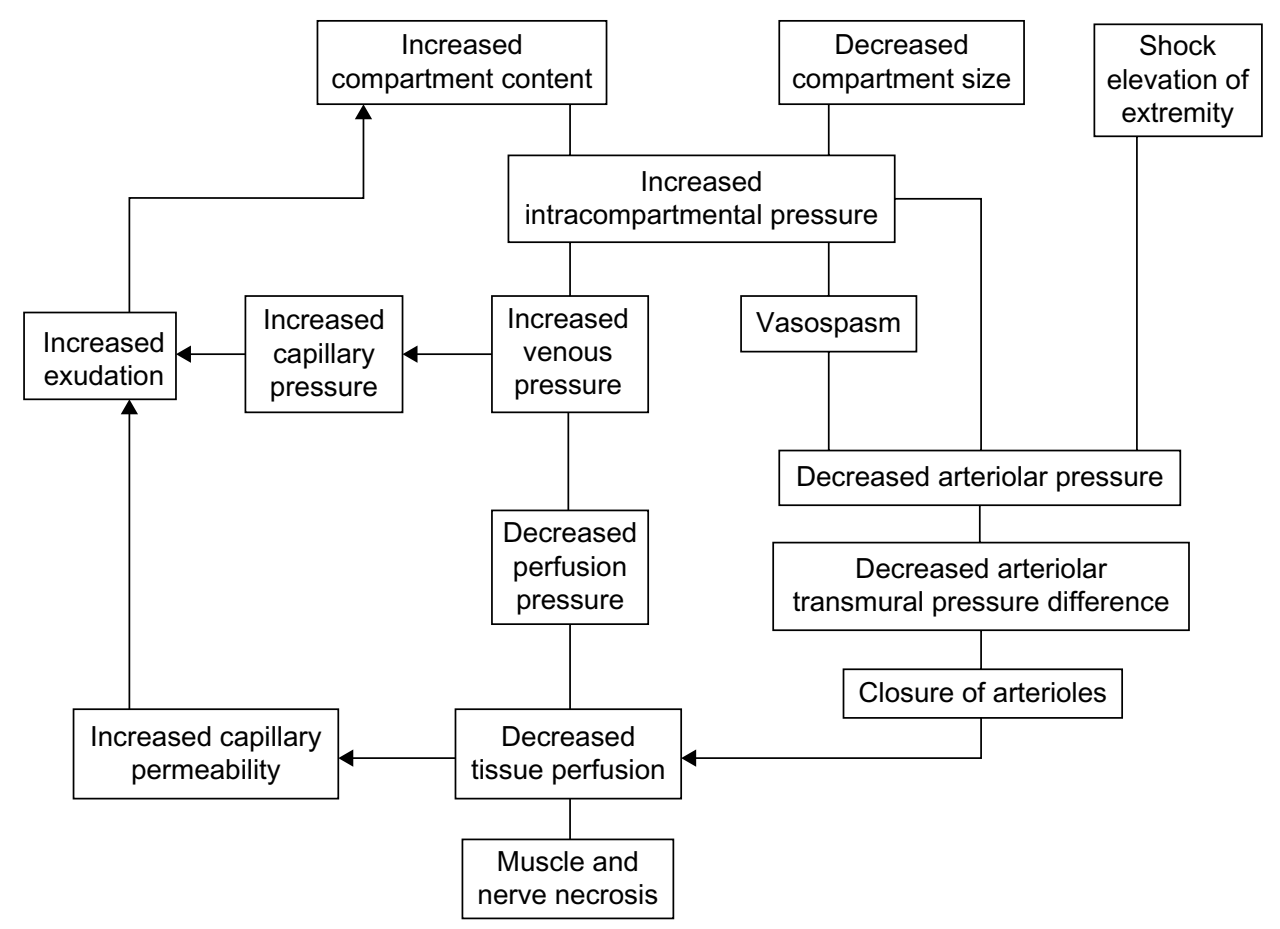

Figure I The vicious cycle of compartment syndrome.

Notes: Copyright (C) 2011 by the American Academy of Orthopaedic Surgeons. Reproduced with permission, from: Prasarn ML, Ouellette EA. Acute compartment syndrome of the upper extremity. Journal of the American Academy of Orthopaedic Surgeons. 201 I;19(1):49-58. Promotional and commercial use of the material in print, digital or mobile device format is prohibited without the permission from the publisher Wolters Kluwer Health. Please contact Iwwjournalpermissions@wolterskluwer.com for further information. ${ }^{4}$

syndrome diagnosis. The increased need for analgesia in a functioning nerve block is also a sign that the patient is developing compartment syndrome. This is breakthrough pain, must be taken seriously, and has been reported to aid the diagnosis of compartment syndrome. ${ }^{27}$

\section{Tests}

Though there are no reproducible and reliable tests for compartment syndrome, ${ }^{8}$ measurement of intracompartmental syndrome is required in cases where diagnosis is unclear.

Traditionally, a value of $30 \mathrm{~mm}$ of $\mathrm{Hg}$ was taken as a cut off value, above which intervention was required. However, the difference in the diastolic pressure and intracompartmental pressure is used more reliably as compartment pressure is dependent on perfusion or the systemic blood pressure. According to Whitesides and Heckman ${ }^{28}$ criteria, compartment syndrome occurs when the pressure increases to $20 \mathrm{mmHg}$ below the diastolic pressure. This stems from the fact that the critical level of pressure above which ischemia results is closely linked to the arterial pressure. Most others intervene when the delta pressure is less than $30 \mathrm{mmHg} .^{7,29}$ Delta pressure, is the difference between the diastolic blood pressure of a patient and the pressure of the compartment measured $(\Delta \mathrm{P}=$ diastolic pressure - intracompartmental pressure). A value of less than or equal to $30 \mathrm{mmHg}$ should be considered diagnostic. ${ }^{7}$
The use of a $\Delta \mathrm{P}$ of $\leq 30 \mathrm{mmHg}$ as a threshold for fasciotomy led to no missed cases of ACS, no unnecessary fasciotomies, and no complications in any patients. ${ }^{30}$

The downside to these measurements is that it results in high false positive results, as seen by Nelson ${ }^{31}$ in which as much as $18 \%-82 \%$ false positive diagnosis was based on $30 \mathrm{mmHg}$ difference between diastolic and compartmental pressure. The criteria for diagnosis are varied, making it difficult to base judgment only on pressure readings. High suspicion must be maintained even if the pressure criteria is not met in patients with increased swelling and rising intracompartmental pressures. ${ }^{4}$

Various techniques such as a wick catheter, slit catheter, the Whiteside's technique, and the Stryker compartment pressure measuring device have been used. ${ }^{18}$ Serial measurements provide more information, and these devices can be used for single or continuous monitoring. A study comparing commonly used modalities for measurement reported that the arterial manometer was the most accurate, followed by the Stryker hand held device (acceptable in terms of accuracy and precision in diagnosis of compartment syndrome). ${ }^{32}$ Figure 2 shows a step by step method on how to use an intracompartmental measurement device. ${ }^{33}$ The placement of the device should be within $5 \mathrm{~cm}$ of the level of the fracture for accurate results. ${ }^{34}$ 
1. Turn monitor on, identify necessary equipment including the pre-filled syringe of sterile normal saline, $18 \mathrm{G}$ needle, and tapered chamber stem (image 1)

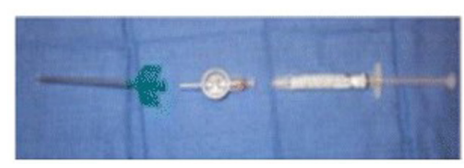

2. Place needle firmly on the tapered chamber stem. Remove cap on pre-filled syringe and secure to the remaining chamber stem

3. Open the monitor's cover and place the needle, stem and syringe into the unit as shown in image 2 . Close the cover to secure the device

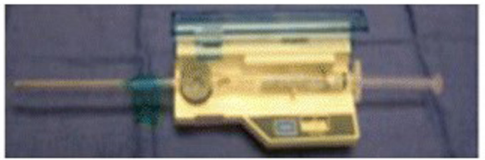

4. Flush fluid from the syringe through the stem and needle until fluid is seen exiting the tip of the needle

5. Hold the unit at the intended angle against the skin prior to insertion. Press the zero button and wait 2 seconds until the display reads 00

6. Insert needle into body. Slowly inject less than $3 / 10 \mathrm{cc}$ of saline into the compartment. Wait for the display to reach equilibrium before reading pressure. Then repeat for all compartments

Figure 2 How to use intracompartmental measurement devices.

Notes: Copyright (C) Hospital for Special Surgery 20I4. Reproduced from: Garner MR, Taylor SA, Gausden E, Lyden JP. Compartment Syndrome: Diagnosis, Management, and Unique Concerns in the Twenty-First Century. HSS J. 20I4; I0(2):143-152. ${ }^{33}$

The accuracy of objective measuring is dependent on factors such as correct use of equipment, position of extremity, the depth of the needle, and the anatomical site of catheter insertion. ${ }^{1}$ Though the anterior compartment of the leg is fairly simple to measure, difficulty is often encountered on measuring the deep posterior compartment of leg. Ultrasound guided catheter insertion was advocated by Wiley et al. ${ }^{35}$ Schepsis et a ${ }^{36}$ described the insertion of the catheter medially at middle and distal thirds of the leg parallel to the posterior surface of the tibia, into the flexor digitorum longus tendon. In the forearm, McCarthy et al described the approach to the volar compartment from the midline of the ulna between the flexor carpi radialis and palmaris longus. ${ }^{37}$ In practice, the catheter is usually inserted as close to the fracture site, and in the compartment clinically suspected to be affected. ${ }^{4}$

Newer technology has been developed, such as near infrared spectroscopy which works on the same principles as pulse oximetry. With the use of differential light reflection and its absorption pattern, proportion of oxygen saturated hemoglobin can be estimated $2-3 \mathrm{~cm}$ below the skin surface. ${ }^{8}$ This could potentially predict neuromuscular ischemia better than compartment perfusion pressure. ${ }^{8}$ Interesting concepts like radiofrequency identification chips for continuous pressure monitoring, and ultrafiltration catheters for diagnosis and treatment protocol have also been described. Further work needs to be established in all these fields, which could be path breaking in the diagnostic and treatment modalities for ACS.

\section{Management}

As mentioned above, diagnosing ACS can be difficult. It is usually diagnosed by clinical examination based on a high index of suspicion and supplemented by tests if necessary. ${ }^{18}$ Once the possibility of ACS is noted, action should be taken immediately.

In 2011, Prasarn and Ouellette ${ }^{4}$ suggested an algorithm for the diagnosis and management of compartment syndrome (Figure 3).

Firstly, removal of any constrictive dressings is a critical step to allow accurate assessment of the limb. Many consider clinical assessment as diagnostic but some may choose to use intracompartmental measures to make a diagnosis. ${ }^{18}$ However, if there is a doubt then the diagnosis of ACS should be considered unless proven otherwise. Many recommend the use of intracompartmental measuring in the obtunded or polytrauma patients and if there is uncertainty. Once the diagnosis is made, the treatment is surgical in the form of fasciotomy. Eaton and Green in $1975,{ }^{38}$ described 


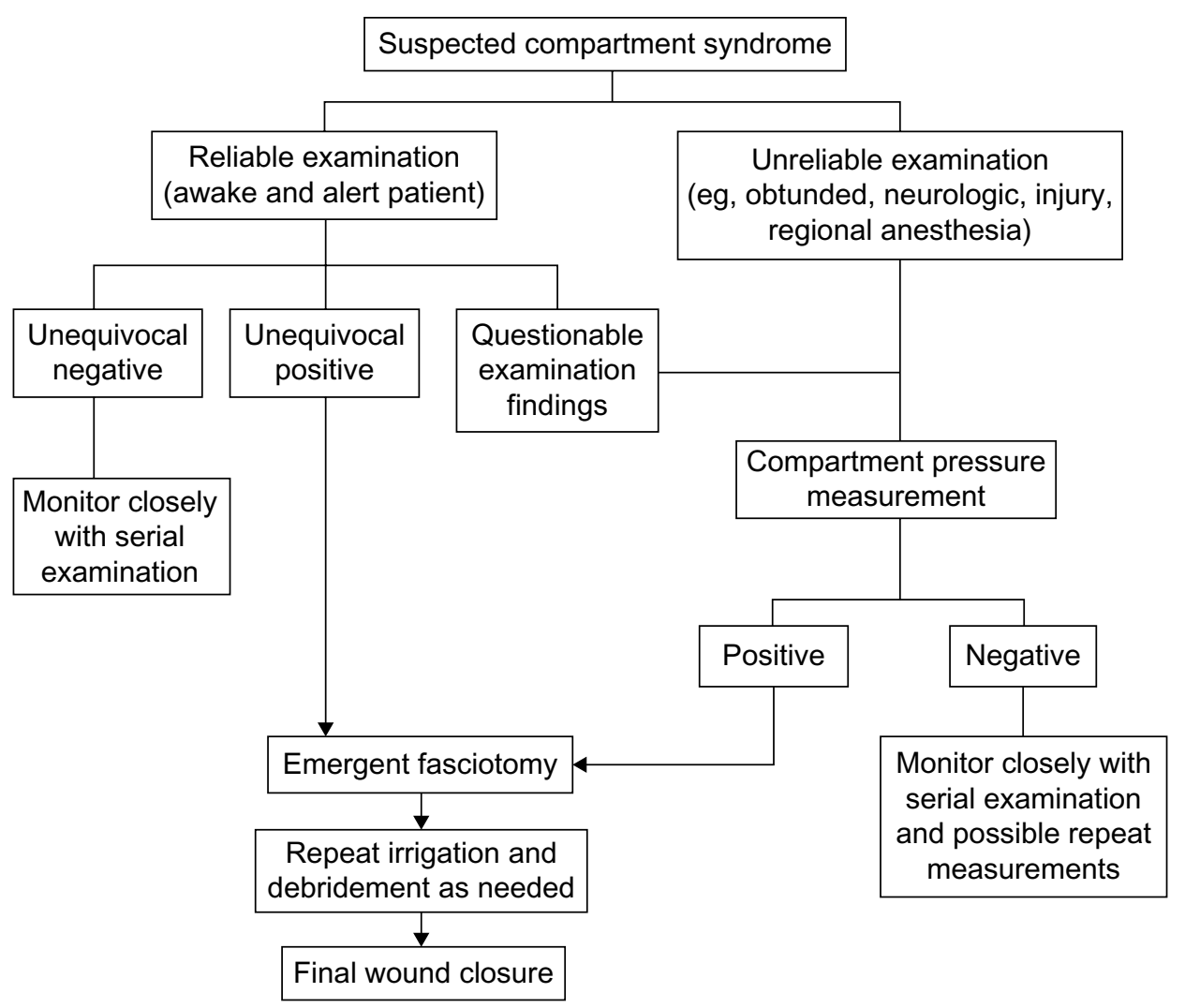

Figure 3 Algorithm for the diagnosis and management of suspected compartment syndrome.

Notes: Copyright (c) 2011 by the American Academy of Orthopaedic Surgeons. Reproduced with permission, from: Prasarn ML, Ouellette EA. Acute compartment syndrome of the upper extremity. Journal of the American Academy of Orthopaedic Surgeons. 201 I;19(1):49-58. Promotional and commercial use of the material in print, digital or mobile device format is prohibited without the permission from the publisher Wolters Kluwer Health. Please contact Iwwjournalpermissions@wolterskluwer.com for further information. ${ }^{4}$

poor results (Volkmann's ischemic contracture) in all patients who did not have fasciotomies despite dynamic splinting and subsequent surgery.

Time is of the essence in managing compartment syndrome. Duckworth et al, ${ }^{7}$ demonstrated that a delay in the time to fasciotomy was predictive of the development of long-term complications. Their findings were in line with the literature for lower limb compartment syndrome where time to fasciotomy has been shown to influence outcome, and a critical time of 6 to 12 hours has been described.

The goal of surgical treatment in ACS is to decompress the involved compartment. This requires urgent decompression of all tight fascial envelopes. It is not recommended to attempt minimal/limited procedures either through smaller incisions or by not decompressing all compartments. This yields poorer results as complete decompression of all fascial and epimysial envelopes cannot be guaranteed. There is also the danger of post-ischemic hyperemia and swelling especially within the 1st hour post-decompression of an ischemic compartment. Secondary compartment syndrome may develop here due to intact compartment envelopes. ${ }^{25}$
Fasciotomy as a procedure, is not without its own risks of wound healing, muscle weakness, chronic venous insufficiency, fracture non-union, and need for subsequent skin grafting. There are several techniques of decompression for different parts of the body. Here we will discuss forearm, leg, hand, and foot decompression techniques.

There are three described compartments in the forearm, the volar (superficial and deep), dorsal, and mobile wad of Henry (lateral) compartment. ${ }^{39}$ Adequate decompression of all involved compartments is mandatory (Figure 4). ${ }^{18}$ The typical volar incision begins $1 \mathrm{~cm}$ proximal and $2 \mathrm{~cm}$ lateral to the medial epicondyle and obliquely crosses the antecubital fossa and over the volar aspect of the mobile wad. The incision then curves in a medial direction, reaching the midline at the junction of the middle and distal third of the forearm. The incision is then continued just medial to the palmaris longus tendon to avoid the palmar cutaneous branch of the median nerve. The incision should cross the wrist crease at an angle and extend into the mid-palm for a carpal tunnel release. ${ }^{18,25}$ The volar incision aims to open the lacertus fibrosus and fascia overlying the flexor carpi ulnaris. 

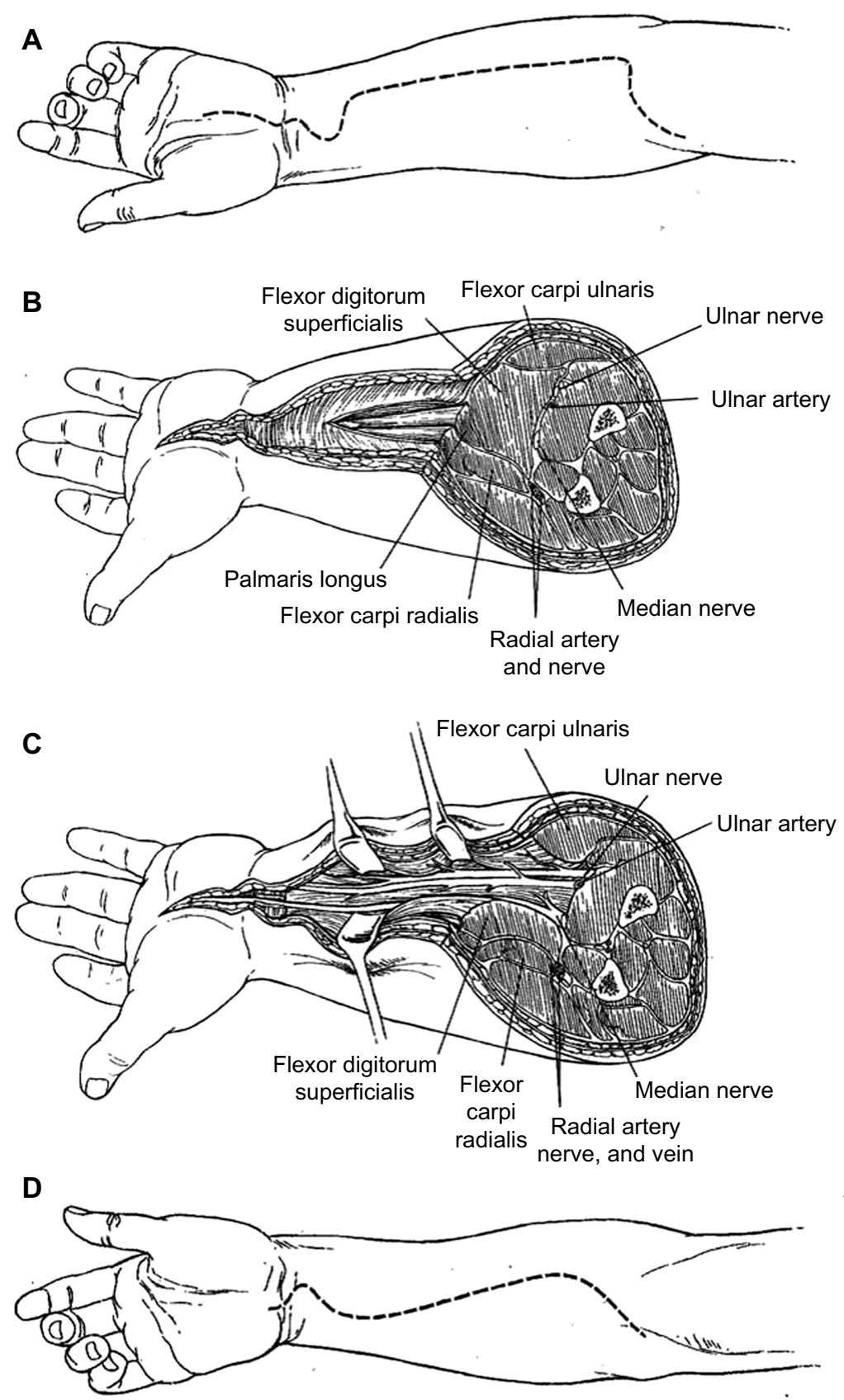

Figure 4 Surgical approaches to the volar compartment of the forearm.

Notes: (A) Skin incision for the ulnar approach. (B) The interval between the flexor carpi ulnaris muscle and the flexor digitorum superficialis muscle. (C) After the ulnar nerve and artery are identified and protected, the fascia over the deep compartment is opened. (D) Incision for the Henry approach, which is performed through the interval between the flexor carpi radialis and the brachioradialis muscles. Copyright $@ 201$ I by the American Academy of Orthopaedic Surgeons. Reproduced with permission, from: Prasarn ML, Ouellette EA. Acute compartment syndrome of the upper extremity. Journal of the American Academy of Orthopaedic Surgeons. 20I I; I9(I):49-58. Promotional and commercial use of the material in print, digital or mobile device format is prohibited without the permission from the publisher Wolters Kluwer Health. Please contact lwwjournalpermissions@wolterskluwer.com for further information. ${ }^{4}$

The flexor carpi ulnaris is retracted ulnarly and the flexor digitorum superficialis is retracted radially to permit opening of the fascia of the deep volar compartment. Care is taken to avoid the ulnar nerve and artery. ${ }^{25}$ For a dorsal compartment release, a dorsal longitudinal incision is made $2 \mathrm{~cm}$ distal to the lateral epicondyle toward the midline of the wrist. ${ }^{40}$ Dissection is done between the interval of extensor digitorum communis and extensor carpi radialis brevis. After decompression, the muscles of the forearm should be palpated and no further action taken if they are soft. If there is residual muscle tension, then an epimysiotomy may be required. ${ }^{25,38}$ 
With regards to hand compartment syndrome, there are ten compartments. The hypothenar, thenar, adductor pollicis, dorsal interosseous (four), volar interosseous (three). Release of the volar and dorsal interosseous compartments and the adductor compartment to the thumb is done with two longitudinal incisions dorsally over the second and fourth metacarpals (Figure 5). The fascia over the dorsal interosseous muscles is incised. Blunt dissection is performed along the ulnar side of the second metacarpal to decompress the first volar interosseous through the more radial incision. Dissecting along the radial aspect of the fourth and fifth metacarpals through the more ulnar incision releases the second and third volar interosseous compartments. To release the thenar and hypothenar compartments, longitudinal incisions are made at the junctions of the glabrous and non-glabrous skin over the radial side of the first metacarpal and the ulnar side of the fifth metacarpal. ${ }^{4}$ Hand fasciotomies should be done by a hand surgeon unless there is an immediate need with no access to a hand surgeon.

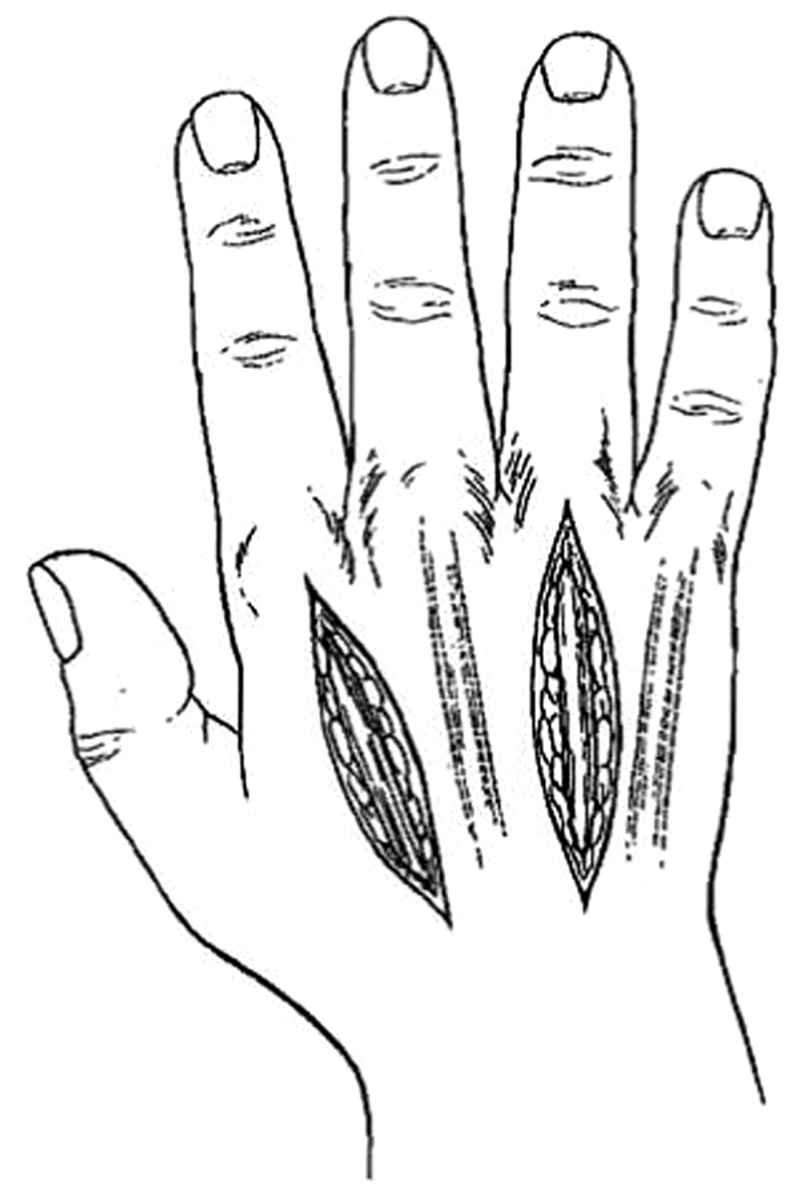

Figure 5 Illustration demonstrating two longitudinal incisions made over the 2nd and 4th metacarpals to release the dorsal and volar interosseous compartments and the adductor compartment of the thumb.

Notes: Reproduced with permission from Elsevier. This figure was published in Hand Clinics; 14(3); Ouellette EA; Compartment syndromes in obtunded patients; 43I-450; Copyright Elsevier 1998. ${ }^{44}$
In the leg, decompression of all four compartments, the anterior, lateral, deep posterior, and superficial posterior compartments, is recommended rather than decompression of a single or some compartments. ${ }^{25}$ The British Orthopaedic Association and The British Association of Plastic and Reconstructive Surgeons recommended a two incision technique (Figure 6). ${ }^{40}$ This includes an anterolateral and posteromedial incision. The incision is $15-18 \mathrm{~cm}$ long. The anterolateral incision is done $2 \mathrm{~cm}$ lateral to the anterior border of the tibia. This decompresses the anterior and peroneal compartments. The superficial peroneal nerve is identified and protected. The fasciotomy of the anterior compartment is performed $1 \mathrm{~cm}$ in front of the intermuscular septum and fasciotomy of the lateral compartment is performed $1 \mathrm{~cm}$ behind the intermuscular septum. The posteromedial incision is done $1-2 \mathrm{~cm}$ medial to the posterior tibial border. The saphenous vein and nerve is protected and the superficial compartment is incised. The soleal bridge is detached from the back of the tibia to adequately decompress the deep posterior compartment. At the time of decompression, if there are underlying fractures, rigid fixation should be considered as it also protects the soft tissues and facilitates access to the wound. Accurate placement of the incisions is important. The medial incision should be anterior to the posterior tibial artery to avoid injury to the perforating vessels that supply the skin used for flaps. The medial $10 \mathrm{~cm}$ perforator is the most reliable and care must be taken (Figure 7).

In the foot, there are nine main compartments; medial, lateral, interosseous (four), and central (three). Dual dorsal incisions are recommended. A dorsal medial incision is made medial to second metatarsal and this releases the first and second interosseous, medial, and deep central compartment. The dorsal lateral incision is made lateral to the fourth metatarsal and releases the third and fourth interosseous, lateral, superficial, and middle central compartments. In order to do this, the dorsal fascia of each interosseous compartment is opened longitudinally and the muscles stripped from the medial fascia in the first interosseous compartment. For this, split adductor compartment and a medial incision may be added for decompression of calcaneal compartment (Figure 8). ${ }^{41}$

After decompression, the wounds should be left open. The limb is splinted and passive range of motion exercises started to prevent contractures. The aim should be to bring the patient back to the operating room in 48-72 hours for a dressing change and skin closure. If this is not possible, then progressive closure can be performed. Wound edge approximation techniques allow progressive approximation of skin edges. This can be done with various techniques 


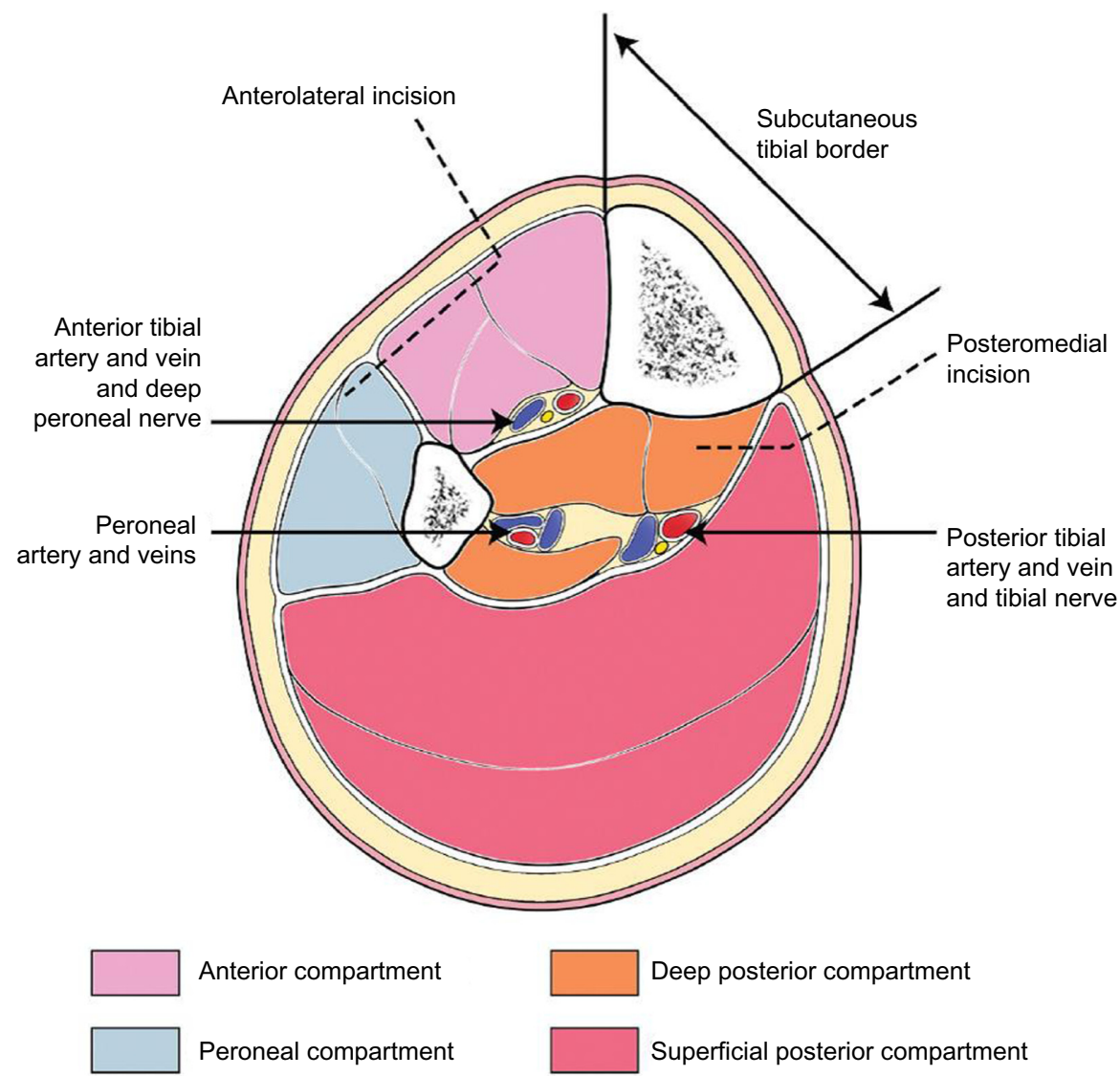

Figure 6 Cross-section through leg showing incisions to decompress all four compartments of the leg.

Notes: Reproduced with permission, from: BOAST 4: The management of severe open lower limb fractures. British Orthopaedic Association, British Association of Plastic, Reconstructive and Aesthetic Surgeons Standard for Trauma 2009. Available from: https://www.boa.ac.uk/wp-content/uploads/20I4/I2/BOAST-4.pdf. Accessed June II, 20I5.40
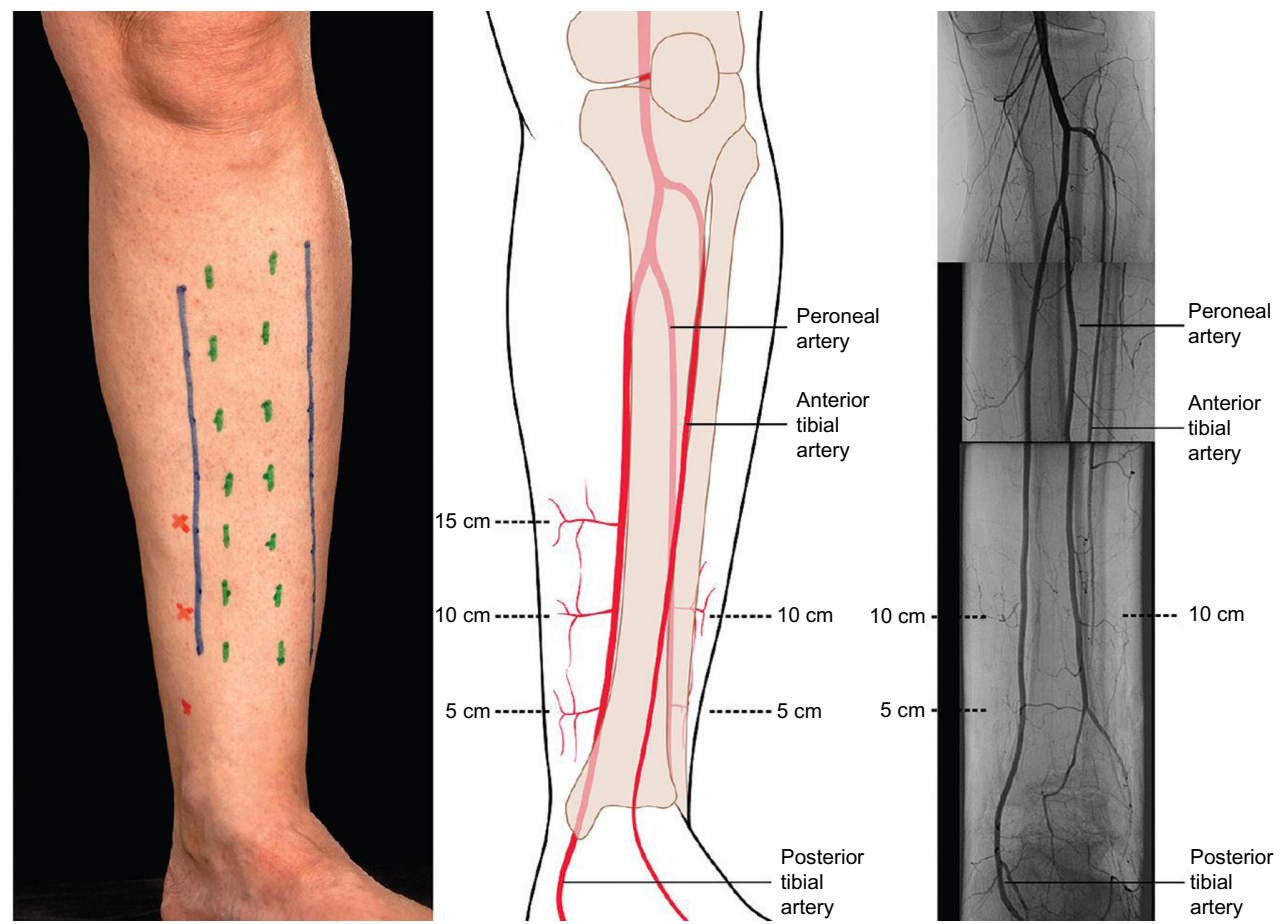

Figure 7 Incision and vessels.

Notes: Reproduced with permission, from: BOAST 4: The management of severe open lower limb fractures. British Orthopaedic Association, British Association of Plastic, Reconstructive and Aesthetic Surgeons Standard for Trauma 2009. Available from: https://www.boa.ac.uk/wp-content/uploads/20 I4/I2/BOAST-4.pdf. Accessed June II, 20I5. ${ }^{40}$ 

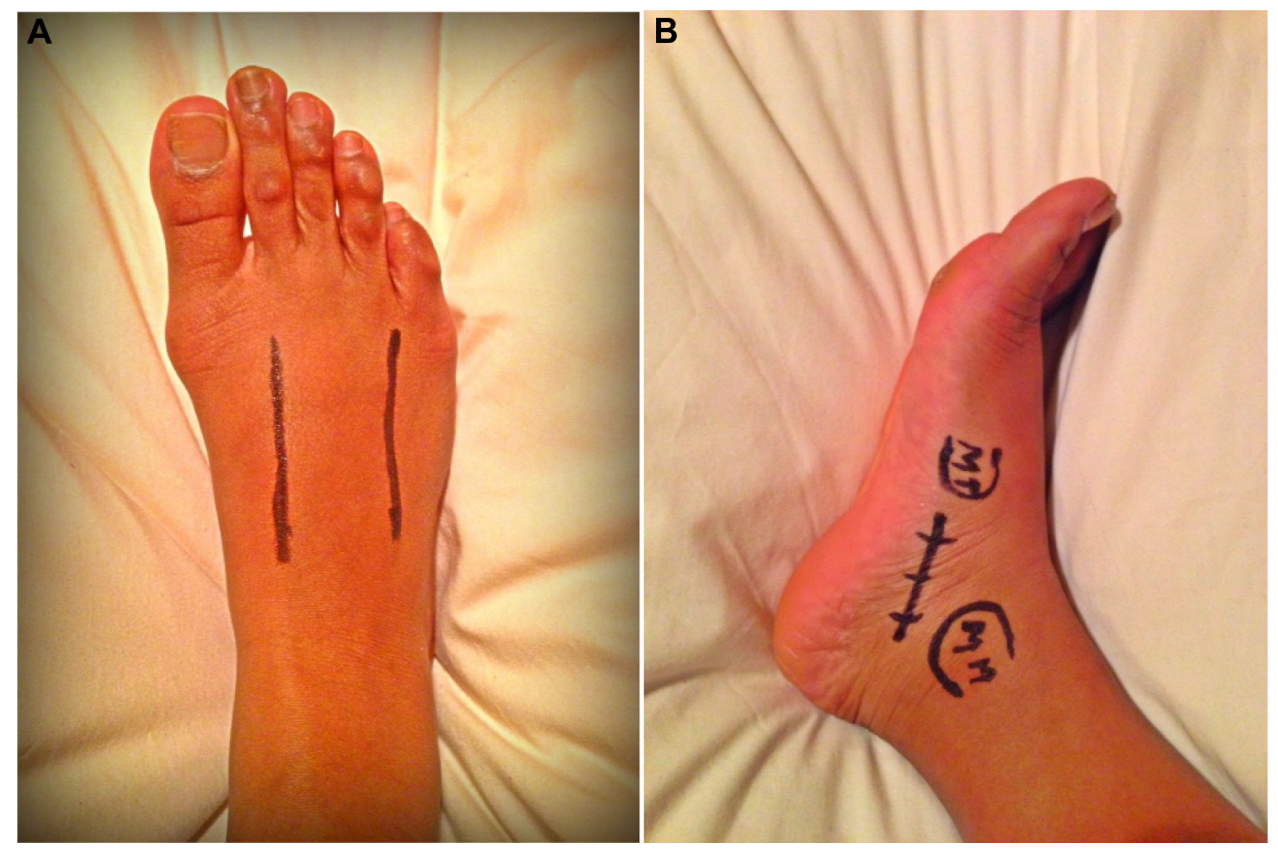

Figure 8 Incision lines.

Notes: (A) Dorsomedial and dorsolateral and medial (B) for decompression.

including boot-lacing, gradual closure with increasing number of sutures or using negative pressure wound therapy.

In some situations, there is a need for split-thickness skin grafting. Younger age and mechanism of injury may play a part here. ${ }^{7}$ The increased bulk in younger patients makes delayed closure without tension more difficult. Crush injuries are more likely to require split skin grafting.

In cases of delayed presentation of compartment syndrome, views of the surgeon may vary regarding whether to perform a fasciotomy. Reported cases in literature however suggest that fasciotomy should be performed as soon as possible once diagnosis is made, with further debridements as necessary. ${ }^{42,43}$

\section{Chronic exertional compartment syndrome}

Treating chronic compartment syndrome, or chronic exertional compartment syndrome is different. Non-surgical treatment can be offered and will only be successful if the patient is willing to give up the activity or the level of activity that causes symptoms. A different form of training can be offered. However, athletes may not want to modify their exercise programs. Therefore subcutaneous fasciotomy of the involved compartment can be considered. Endoscopically assisted fasciotomy has also been described by Fraipont and Adamson with good results especially in reducing pain. ${ }^{1}$ Endoscopically assisted, two incision fasciotomy or single incision fasciotomy can be performed. The advantages of endoscopic release in the lower extremity are access to the entire length of the compartment and visualization of the superficial peroneal nerve and its branches. ${ }^{1}$

\section{Conclusion}

Compartment syndrome is a surgical emergency. An accurate diagnosis can usually be made on the basis of a good history and thorough clinical examination. If there is any doubt, a calibrated intracompartmental measuring device should be used to aid with diagnosis. The recommended treatment for proven ACS is adequate decompression of the involved compartment with a fasciotomy and subsequent closure of the wound at a later date. A split skin graft may be necessary for closure of the wound.

ACS is a serious clinical condition and every care must be taken to treat this condition as soon as possible. Although it is often noted as an orthopedic emergency, it is actually a surgical emergency and every clinician must be able to diagnose it promptly and the surgeon must be able to treat or respond to it adequately.

\section{Disclosure}

The authors have no conflicts of interest to disclose in this work. 


\section{References}

1. Fraipont MJ, Adamson GJ. Chronic Exertional Compartment Syndrome J Am Acad Orthop Surg. 2003;11(4):268-276.

2. McDonald S, Bearcroft P. Compartment syndromes. Semin Musculoskelet Radiol. 2010;14(2):236-244.

3. Wright E. Neurovascular impairment and compartment syndrome. Paediatric Nurs. 2009;21(3):26-29.

4. Prasarn ML, Ouellette EA. Acute compartment syndrome of the upper extremity. J Am Acad Orthop Surg. 2011;19(1):49-58.

5. Badge R, Hemmady M. Forearm Compartment Syndrome following Thrombolytic Therapy for Massive Pulmonary Embolism: A Case Report and Review of Literature. Case Rep Orthop. 2011;2011:678525.

6. Bhattacharyya T, Vrahas MS. The Medical-Legal Aspects of Compartment Syndrome. J Bone Joint Surg Am. 2004;86-A(4):864-868.

7. Duckworth AD, Mitchell SE, Molyneux SG, White TO, Court-Brown CM, McQueen MM. Acute Compartment Syndrome of the Forearm. J Bone Joint Surg Am. 2012;94(10):e63.

8. Harvey EJ, Sanders DW, Shuler MS, et al. What's New in Acute Compartment Syndrome? J Orthop Trauma. 2012;26(12):699-702.

9. McQueen MM, Gaston P, Court-Brown CM. Acute compartment syndrome. Who is at risk? J Bone Joint Surg Br. 2000;82(2):200-203.

10. Percival TJ, White JM, Ricci MA. Compartment syndrome in the setting of vascular injury. Perspect Vasc Surg Endovasc Ther. 2011;23(2): $119-124$.

11. Reuben A and Clouting E. Compartment syndrome after thrombolysis for acute myocardial infarction. Emerg Med J. 2005;22(1):77.

12. Haggis $\mathrm{P}$, Yates $\mathrm{P}$, Blakeway $\mathrm{C}$, et al. Compartment syndrome following total knee arthroplasty. J Bone Joint Surg Br. 2006;88(3): 331-334.

13. Ojike NI, Roberts CS, Giannoudis PV. Compartment syndrome of the thigh: a systematic review. Injury. 2010;41(2):133136.

14. Ojike NI, Roberts CS, Giannoudis PV. Foot compartment syndrome: a systematic review of the literature. Acta Orthop Belg. 2009;75(5): 573-580.

15. Fulkerson E, Razi A, Tejwani N. Review: acute compartment syndrome of the foot. Foot Ankle Int. 2003;24(2):180-187.

16. Henson JT, Roberts CS, Giannoudis PV. Gluteal compartment syndrome. Acta Orthop Belg. 2009;75(2):147-152.

17. Liu HL, Wong DS. Gluteal compartment syndrome after prolonged immobilisation. Asian J Surg. 2009;32(2):123-126.

18. Kalyani BS, Fisher BE, Roberts CS, Giannoudis PV. Compartment Syndrome of the Forearm: A Systematic Review. J Hand Surg Am. 2011;36(3):535-543.

19. Elliott KGB, Johnstone AJ. Diagnosing acute compartment syndrome. J Bone Joint Surg Br. 2003;85(5):625-632.

20. Hwang RW, de Witte PB, Ring D. Compartment syndrome associated with distal radial fracture and ipsilateral elbow injury. $J$ Bone Joint Surg Am. 2009;91(3):642-645.

21. Amsdell SL, Hammert WC. High-pressure injection injuries in the hand: current treatment concepts. Plast Reconstr Surg. 2013;132(4): 586e-591e.

22. Grottkau BE, Epps HR, Di Scala C. Compartment syndrome in children and adolescents. J Pediatr Surg. 2005;40(4):678-682.

23. Bae DS, Kadiyala RK, Waters PM. Acute compartment syndrome in children: contemporary diagnosis, treatment, and outcome. J Pediatr Orthop. 2001;21(5):680-688.

24. Lawendy AR, Sanders DW, Bihari A, Parry N, Gray D, Badhwar A. Compartment syndrome-induced microvascular dysfunction: an experimental rodent model. Can J Surg. 2011;54(3):194-200.

25. Matsen FA 3rd, Winquist RA, Krugmire RB Jr. Diagnosis and management of compartmental syndromes. J Bone Joint Surg Am. 1980;62(2): 286-291.
26. Uzel AP, Steinmann G. Thigh compartment syndrome after intramedullary femoral nailing: possible femoral nerve block influence on diagnosis timing. Orthop Traumatol Surg Res. 2009;95(4):309-313.

27. Aguirre JA, Gresch D, Popovici A, Bernhard J, Borgeat A. Case Scenario: Compartment Syndrome of the Forearm in Patient with an Infraclavicular Catheter: Breakthrough Pain as Indicator. Anaesthesiology. 2013; 118(5):1198-1205.

28. Whitesides TE, Heckman MM. Acute compartment syndrome: Update on diagnosis and treatment. J Am Acad Orthop Surg. 1996;4(4): 209-218.

29. Frink M, Hildebrand F, Krettek C, Brand J, Hankemeier S. Compartment syndrome of the lower leg and foot. Clin Orthop Relat Res. 2010;468(4): 940-950.

30. McQueen MM, Court-Brown CM. Compartment monitoring in tibial fractures: the pressure threshold for decompression. J Bone Joint Surg Br. 1996;78(1):99-104.

31. Nelson JA. Compartment pressure measurements have poor specificity for compartment syndrome in the traumatized limb. J Emerg Med. 2013;44(5):1039-1044.

32. Boody AR, Wongworawat MD. Accuracy in the Measurement of Compartment Syndrome: A Comparison of three commonly used devices. J Bone Joint Surg Am. 2005;87(11):2415-2422.

33. Garner MR, Taylor SA, Gausden E, Lyden JP. Compartment Syndrome: Diagnosis, Management, and Unique Concerns in the Twenty-First Century. HSS J. 2014;10(2):143-152.

34. Duckworth AD, Mcqueen MM. Focus on Diagnosis of acute compartment syndrome. The Journal of Bone and Joint Surgery. 2011.

35. Wiley JP, Short WB, Wiseman DA, Miller SD. Ultrasound catheter placement for deep posterior compartment pressure measurements in chronic compartment syndrome. Am J Sports Med. 1990;18(1):74-79.

36. Schepsis AA, Fitzgerald M, Nicoletta R. Revision surgery for exertional anterior compartment syndrome of the lower leg: technique, findings, and results. Am J Sports Med. 2005;33(7):1040-1047.

37. McCarthy DM, Sotereanos DG, Towers JD, Britton CA, Herndon JH. A cadaveric and radiologic assessment of catheter placement for the measurement of forearm compartment pressures. Clin Orthop Relat Res. 1995;(312):266-270.

38. Eaton RG, Green WT. Volkmann's ischemia: a volar compartment syndrome of the forearm. Clin Orthop Relat Res. 1975;(113):58-64.

39. orthobullets.com [homepage on the Internet]. Karadsheh M. Hand and Forearm Compartment Syndrome: Orthobullets; 2014. Available from: http://www.orthobullets.com/trauma/1064/hand-and-forearmcompartment-syndrome/. Accessed June 11, 2015.

40. BOAST 4: The management of severe open lower limb fractures. British Orthopaedic Association, British Association of Plastic, Reconstructive and Aesthetic Surgeons Standard for Trauma 2009. Available from: https://www.boa.ac.uk/wp-content/uploads/2014/12/BOAST-4.pdf. Accessed June 11, 2015.

41. orthobullets.com [homepage on the Internet]. Karaddsheh M. Foot Compartment Syndrome. Orthobullets; 2014. Available from: http:// www.orthobullets.com/trauma/1065/foot-compartment-syndrome/. Accessed June 11, 2015.

42. Gaines RJ, Randall CJ, Browne KL, Carr DR, Enad JG. Delayed Presentation of Compartment Syndrome of the Proximal Lower Extremity After Low-Energy Trauma in Patients Taking Warfarin. Am J Orthop (Belle Mead NJ). 2008;37(12):E201-E204.

43. Mithofer K, Lhowe DW, Altman GT. Delayed Presentation of acute compartment syndrome after contusion of the thigh. J Orthop Trauma. 2002;16(6):436-438.

44. Ouellette EA. Compartment syndromes in obtunded patients. Hand Clin. 1998;14(3):431-450. 
Orthopedic Research and Reviews

Dovepress

\section{Publish your work in this journal}

Orthopedic Research and Reviews is an international, peer-reviewed, open access journal focusing on the patho-physiology of the musculoskeletal system, trauma, surgery and other corrective interventions to restore mobility and function. Advances in new technologies, materials, techniques and pharmacological agents are particularly welcome. The journal welcomes

original research, clinical studies, reviews \& evaluations, expert opinion and commentary, case reports and extended reports. The manuscript management system is completely online and includes a very quick and fair peer-review system, which is all easy to use. Visit http://www.dovepress. com/testimonials.php to read real quotes from published authors.

Submit your manuscript here: http://www.dovepress.com/orthopedic-research-and-reviews-journal 